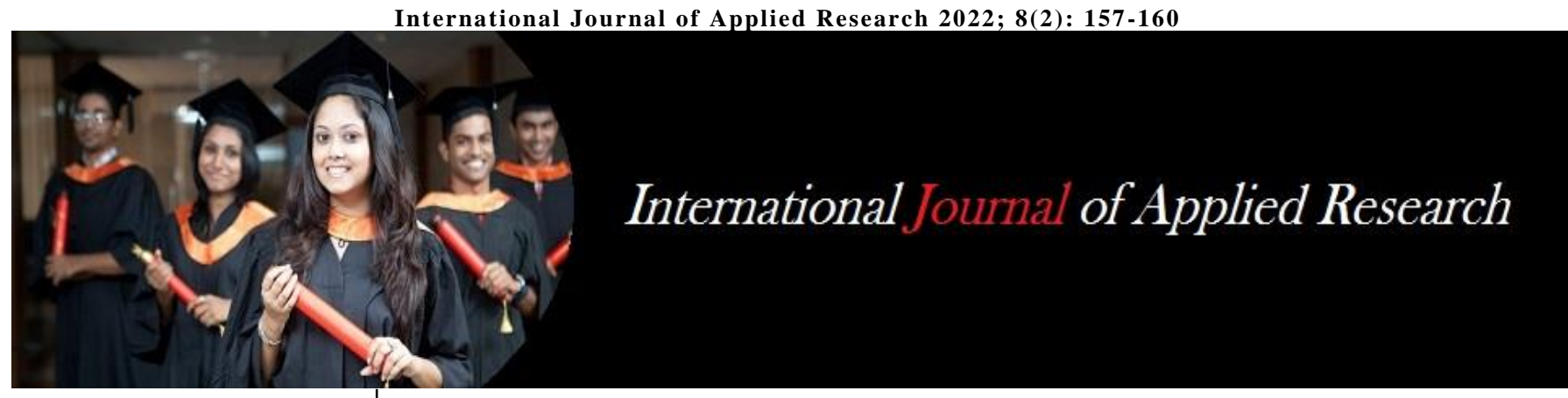

ISSN Print: 2394-7500

ISSN Online: 2394-5869

Impact Factor: 8.4

IJAR 2022; 8(2): 157-160

www.allresearchjournal.com

Received: 01-12-2021

Accepted: 05-01-2022

Anjali Beelwal

Resident Microbiology, Umaid

Hospital, Dr. SNMC, Jodhpur,

Rajasthan, India

Richa Agrawal

Senior Demonstrator,

Department of Microbiology,

Dr. SNMC, Jodhpur,

Rajasthan, India

\section{Eshank Gupta}

Senior Demonstrator,

Department of Microbiology,

Dr. SNMC, Jodhpur,

Rajasthan, India

Pooja Nareda

Resident Microbiology, Umaid

Hospital, Dr. SNMC, Jodhpur,

Rajasthan, India

\section{Vishakha Asopa}

Senior Demonstrator,

Department of Microbiology,

Dr. SNMC, Jodhpur,

Rajasthan, India

\section{Dr. Prabhu Prakash}

Professor, Department of Microbiology, Dr. SNMC, Jodhpur, Rajasthan, India
Corresponding Author: Dr. Prabhu Prakash Professor, Department of Microbiology, Dr. SNMC, Jodhpur, Rajasthan, India

\section{Myiasis by Dermatobia hominis larvae in a post- menopausal patient having ulcerative vulvar carcinoma}

\author{
Anjali Beelwal, Richa Agrawal, Eshank Gupta, Pooja Nareda, Vishakha \\ Asopa and Dr. Prabhu Prakash
}

DOI: https://doi.org/10.22271/allresearch.2022.v8.i2c.9401

\section{Abstract}

68 years old, post-menopausal, multiparous, female having carcinoma of vulva extending up to urethra. She was having foul smelling blood stained discharge with poor personal hygiene was referred from a primary health centre. On examination there was large necrotic cauliflower like growth at labia majora and large number of larva of Dermatobia hominis were crawling in necrotic tissue. Larvae were removed followed by cleansing of the affected area and a course of antibiotics was given. Patient was referred to Oncology Deptt. for further management of vulvar malignancy.

Keywords: myiasis, maggots' infestation, USG, vulvar

\section{Introduction}

The cases of myiasis are worldwide, most of all have been reported from subtropical, tropical and warm- temperate regions. Myiasis is derived from Greek myia which means fly ${ }^{[1]}$. Myiasis is the infestation by dipterous larvae or maggots of various fly species of veterinary and medical interest which feed on living or necrotic tissue of the host and leads to secondary bacterial infections ${ }^{[2,3]}$. Cutaneous, nasopharyngeal, ophthalmic myiasis are common ${ }^{[4,5,6]}$, but genital myiasis is a rare condition ${ }^{[7]}$. Human genital myiasis is usually associated with poor personal hygiene ${ }^{[7]}$, diabetes mellitus, ulcerative lesion and malignancies ${ }^{[8,9]}$. Rare cases of myiasis are reported in post partum patients with uterine fibroids in Western Rajasthan ${ }^{[10]}$. We report a case of urogenital myiasis in a post menopausal Vulvar Carcinoma patient by Dermatobia hominis larvae.

\section{Case Report}

A 68 years old female patient came to tertiary level hospital with the history of fall 10 to 15 days back, ulcer in vulvar region with bleeding per vaginal and pain since two months. On general examination she was conscious and oriented. Menopause 17 year back, No history of sterilization, patient was anemic. C/O Bleeding per vagina and pain since 2 months, cellulitis at gluteal region. Obstetric History- $\mathrm{G}_{6} \mathrm{P}_{6} \mathrm{~L}_{6}$.

On Gross examination of vulva there was large necrotic cauliflower like growth present at right labia majora, full of maggots. On per vaginal examination it was found that vagina was obliterated with large indurated growth and cervix couldn't be reached due to painful condition. Vulvar biopsy was done and sent for Histopathological examination which showed poorly differentiated malignancy. On routine blood investigation Hemoglobin level was low $(08.2 \mathrm{~g} \%)$, total and differential leukocytes count was within normal range. Complete urine examination was within normal limits. Her blood sugar was $95 \mathrm{mg} / \mathrm{dl}$. Blood pressure was within normal limit. She was tested negative for human immunodeficiency virus (HIV) and syphilis (by Rapid Plasma Reagin card test) serological tests. Vulvar necrotic tissue was received in microbiology laboratory for culture and sensitivity and identification of larvae. Necrotic tissue was kept in a sterile Petridis and large number of milky white larvae were crawling in necrotic tissue. 
Microscopic examination of larvae was done under 10X and 40X. (Figure Number -Image of larvae). On basis of morphology it was identified as larvae of Dermatobia hominis ${ }^{[11,12]}$.

Treatment: Visible larvae were removed and then treated with tab diclofenic, vit $b$, and $c$, tab. serratiopeptidase, cap.
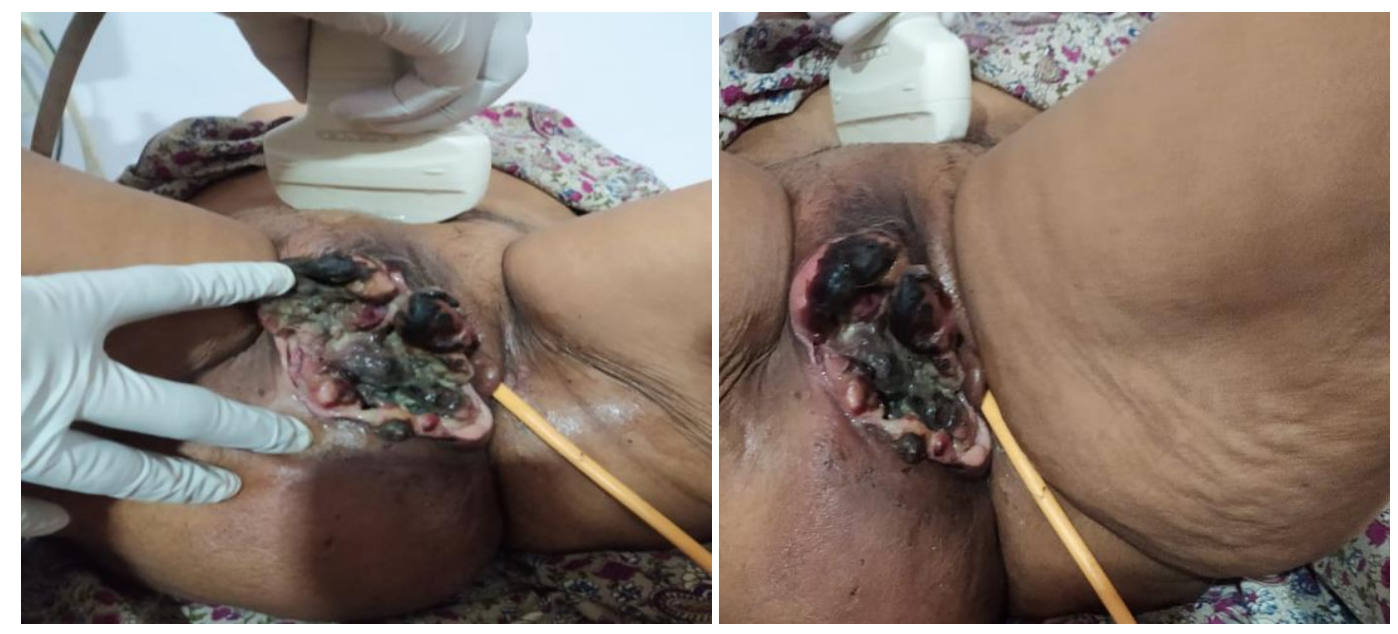

Fig 1, 2: Ulcerative lesion at vulva with numerous larvae
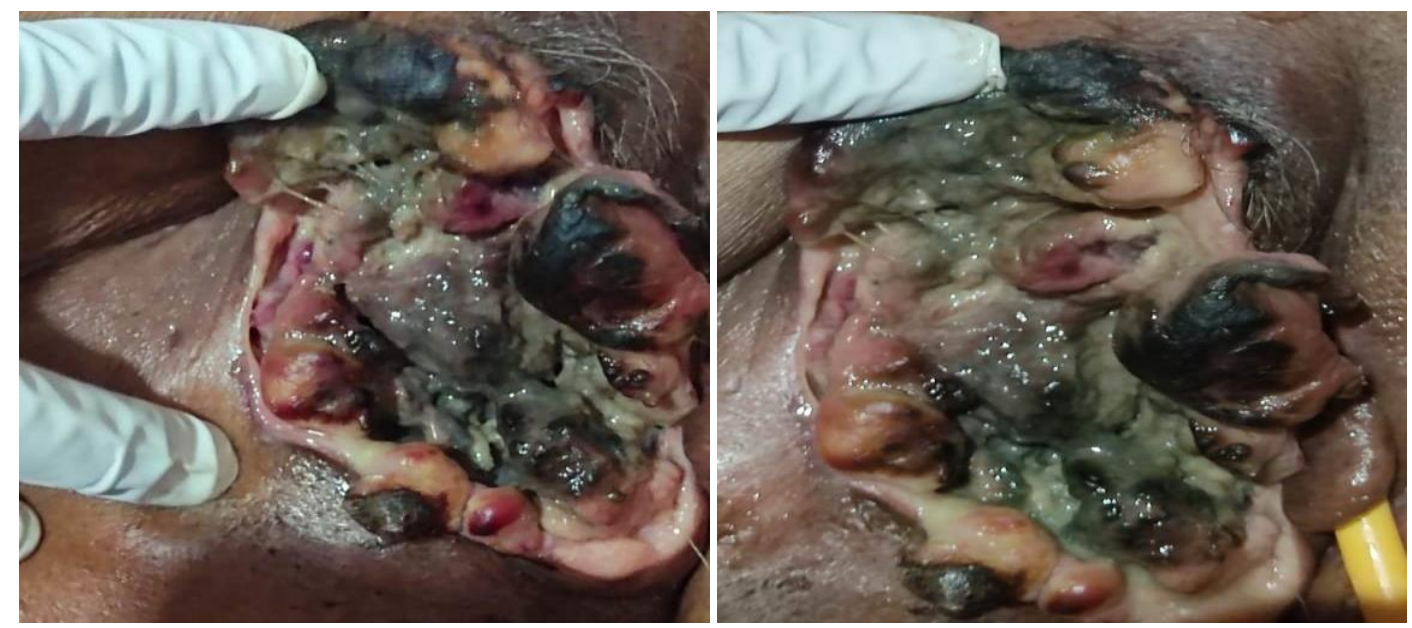

Fig 3, 4: Ulcerative lesion at vulva with numerous larvae
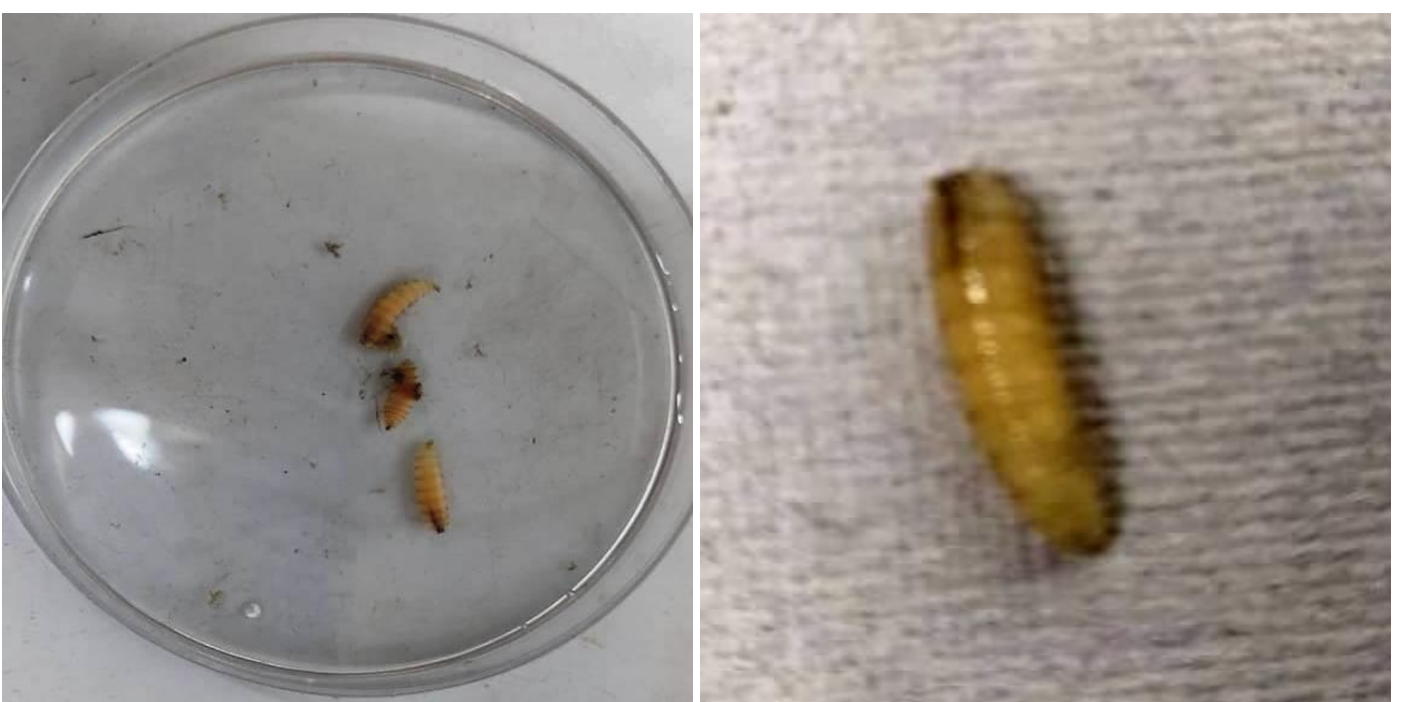

Fig 5, 6: Maggots in a Petri dish and as seen by Hand lense. 


\section{Discussion}

The cases of myiasis are worldwide; most of all have been reported from subtropical, tropical and warm- temperate regions. Myiasis occurs predominantly in rural areas with poor hygiene and low education level ${ }^{[3]}$. Mucocutaneous type is the most common type of myiasis ${ }^{[5]}$. Genital myiasis can be external or internal (internal myiasis is rare), external genital myiasis is most common in females and clitoris, vulva, vagina and uterus have been found affected ${ }^{[14]}$. Myiasis of vulva constitutes only $0.7 \%$ of total human myiasis ${ }^{[15]}$. Myiasis is infection with a fly larva, usually occurring in tropical and subtropical areas. There are several ways for flies to transmit their larvae to people. Some flies deposit their eggs on or near a wound or sore, the larvae that hatch burrow into the skin. Certain species' larvae will move deeper in the body and cause severe damage. Some flies attach their eggs to mosquitoes, other flies or ticks and wait for those insects to bite people. Their larvae then enter these bites ${ }^{[15]}$. One type of fly found in Africa lays its eggs on the ground or on damp cloth such as clothing or bed linens that are hung out to dry. The larvae hatch from the eggs and people get infected by contact with the ground or clothes that have fly larvae attached to them.

For the management of such a case, cleansing of the wound with disinfectant, use of Ivermectin and local application of turpentine oil prevents growth of maggots. The larvae should always be collected and should be sent for entomological analysis. Cultures are recommended to rule out an active bacterial infection and secondary sepsis.

Turpentine oil or white petroleum jelly can be used for eradication of the larvae especially in cutaneous myiasis ${ }^{[4,5]}$ but not much literature is there for its use in vulvar myiasis $[14,15]$. Both of them aim to deprive the larvae of its oxygen supply by blocking the respiratory spiracles, thereby killing them. However, in case of immature larvae, they should be best left to develop for a while as their removal is quite difficult and it can incite a severe inflammatory reaction ${ }^{[15]}$. The present case was an illiterate, multiparous women, belongs to poor rural background family with poor personal hygiene habits. Perhaps due to carcinoma of vulva patient had continuous bleeding, there was open wound and patient was not used to wear undergarments or she never used sanitary napkins. Hence due to poor sanitation and poor hygiene, it attracted flies and laid eggs on open wound.

Myiasis is a disease of poor hygiene ${ }^{[7]}$. Hence, it is our duty to educate patients regarding the maintenance of good hygiene and also, the practice of using sanitary napkins safe and wearing undergarments and ironed, dry, clothes. It is also our duty to consider and not overlook myiasis as a differential diagnosis when any patient with such predisposing factors presents to us with itching or other complaints in the genitourinary area.

\section{Take home message}

1. Human genital myiasis is a rare condition. If there is suspicion of myiasis contact your health care provider for proper diagnosis and care. The larvae need to be surgically removed by a medical professional. Typically, the wound is cleaned daily after the larvae are removed.

2. Proper hygiene of wounds is very important when treating myiasis, medication is given, depending on the type of larva that causes the problem.
3. Extra care should be taken in tropical areas. Skin should be covered to limit the area open to bites from flies, mosquitoes, and ticks. As myiasis doesn't spread from person to person. The only way to get myiasis is through flies, ticks, and mosquitoes.

4. In areas where myiasis is known to occur, use of window screens and mosquito nets are advised. In tropical areas, iron any clothes that are used.

\section{Conclusion}

Human genital myiasis is a rare occurrence, proper counseling of all females about personal health hygiene and to promote them to use good quality of sanitary napkins can prevent this. If infestation of maggots occurs then the management of the patient with Ivermectin and the use of turpentine oil produced excellent results sufficient to stop the further development of maggots into adult form. Mechanical removing of the maggots sometimes results in damage to the larvae with retention of larval fragments in the lesion.

\section{References}

1. Janovy J, Schmidt, Larry S, Gerald D. Schmidt \& Larry S. Roberts' Foundations of Parasitology. In: Roberts S, Larry S, Gerald D, editors. Dubuque, Iowa: Wm. C. Brown, 1996. ISBN 0-697-26071-2

2. James V, Karen C, Guido F, James J, Marie L, David W. Manual of Clinical Microbiology $10^{\text {th }}$ edition, 2, 2267-2268.

3. Burgess IF. Myiasis: Maggot infestation. Nurs Times. 2003;99:51-3.

4. Kudur MH, Pooja M, Nayak S. Unusual presentation of cutaneous myiasis. Indian J Dermatol Venereol Leprol. 2010;76:712-4.

5. Baskaran M, Jagan Kumar B, Geeverghese A. Cutaneous myiasis of face. J Oral Maxillofac Pathol. 2007;11:70-2.

6. Punit Singh K, Prabhu Prakash, Subhadra Singh, Manju Singh, Shanker Singh Shekhawat, Chandrashekhar Vyas, et al Ophthalmomyiasis Externa Caused by Muscae Fly Larva in Deserts of the Thar. Ocular Immunology and Inflammation. 2012; 20:(2)145-147. DOI: $10.3109 / 09273948.2012 .655399$

7. Amandeep Singh, Jasneet Kaur, Occurrence of human urogenital myiasis due to neglected personal hygiene: a review, Transactions of The Royal Society of Tropical Medicine and Hygiene, 2019, 113, (1).

8. Baidya J. A rare case of genital myiasis in a woman with genital prolapse and malignancy and review of the literature. Ann Trop Med Public Health. 2009;2:29-30.

9. Gopalakrishnan S. Myiasis in different types of carcinoma cases in Southern India. Indian $\mathbf{J}$ Med Microbiol. 2008;26:189-192.

10. Asopa V, Verma U, Nareda P, Gupta E, Prakash P: Postpartum genital myiasis - Dermatobia hominis infestation with giant uterine fibroid: A rare case with review of literature Tropical Parasitology. 2020;10(2):142-146 DOI:10.4103/tp.TP_65_19

11. Roberts LS, Janovy J Jr. Parasitic insects: Diptera flies. In: Schmidt GD, Roberts LS, editors. Foundations of Parasitology. $8^{\text {th }}$ ed. Dubuque, New York: The McGraw-Hill Companies, Inc, 2009, 601-25.

12. Francesconi F, Lupi O. Myiasis. Clin Microbiol Rev 2012;25:79-105. 
13. Purnima U, Varshney U, Jahan M. A rare case of genital myiasis in a woman with psychiatric disturbance. CHRISMED J Health Res 2017;4:55-8.

14. Gupta S, Mirza N, Simlot A, Meena K. A rare case of vulvar myiasis International Journal of Applied Research 2018;4(3):303-305

15. Passos MR, Carvalho AV, Dutra AL, Goulart Filho RA, Barreto NA, Salles RS, et al. Vulvar myiasis. Infect Dis Obstet Gynecol 1998;6:69-71.

16. Patel BC, Ostwal S, Sanghavi PR, Joshi G, Singh R. Management of Malignant Wound Myiasis with Ivermectin, Albendazole, and Clindamycin (Triple Therapy) in Advanced Head-and-Neck Cancer Patients: A Prospective Observational Study. Indian J Palliat Care. 2018 Oct-Dec;24(4):459-464.

doi: 10.4103/IJPC.IJPC_112_18. 